\title{
Editorial
}

\section{Advances in Building Technologies and Construction Materials 2016}

\author{
J. M. P. Q. Delgado, ${ }^{1}$ Robert Černý, ${ }^{2}$ A. G. Barbosa de Lima, ${ }^{3}$ and A. S. Guimarães ${ }^{1}$ \\ ${ }^{1}$ CONSTRUCT-LFC, Faculty of Engineering, University of Porto, Rua Dr. Roberto Frias, s/n, 4200-465 Porto, Portugal \\ ${ }^{2}$ Department of Materials Engineering and Chemistry, Faculty of Civil Engineering, Czech Technical University in Prague, \\ Thákurova 7/2077, 16629 Prague 6, Czech Republic \\ ${ }^{3}$ Department of Mechanical Engineering, Federal University of Campina Grande, 58429-900 Campina Grande, PB, Brazil \\ Correspondence should be addressed to J. M. P. Q. Delgado; jdelgado@fe.up.pt
}

Received 7 November 2016; Accepted 13 November 2016

Copyright (C) 2016 J. M. P. Q. Delgado et al. This is an open access article distributed under the Creative Commons Attribution License, which permits unrestricted use, distribution, and reproduction in any medium, provided the original work is properly cited.

The construction industry plays an important key role in socioeconomic development. Building materials, which account for $50 \%-80 \%$ of the total value of construction, form a key factor in the construction sector's response to the needs of human settlement. On the other hand, the appropriateness of building materials and alternative technologies is a crucial factor in the context of exploring the problems of building materials industry in regard to the provision of housing.

Following the great progress made in civil engineering and building materials this special issue aimed at providing a compilation of the state-of-the-art development in building technology and construction building materials. Emphasis was given to basic methodologies, scientific development, and engineering applications.

New advanced materials offer opportunities to change the way in which we construct and retrofit buildings. They give added value in terms of increased performance and functionality. The reduction of carbon footprint for construction materials can start at the production phase, where energy efficient processes can be developed and waste or recycled materials can be employed. New materials can also help address the new challenges of durability in a changing climate.

This special issue is the result of the huge success presented by the previous special issue [1], as the previous special issue had a great acceptation by the scientific community with 85 papers submitted and 33 papers accepted for publication.

A considerable number of experimental and numerical papers address new research advances and applications in concrete material. J. Y. Oh et al. study experimentally the reinforced concrete column encased in prefabricated permanent thin-walled steel form; J. W. Park et al. investigate the fundamental properties of magnesium phosphate cement mortar for rapid repair of concrete; N. Ferhoune et al. present the axial bearing capacity of thin welded rectangular steel stubs filled with concrete sand; M. S. Kim and Y. H. Lee discuss the experimental results on the flexural behaviour and deflections of posttensioned concrete flat plates depending on tendon layout; M. Zhou et al. study the influence of fines content, methylene blue value, and lithology of crushed sand on frost durability, investigate the strength of concrete, and compare the frost durability and strength of crushed sand concrete and river sand concrete; $\mathrm{C}$. $\mathrm{Hu}$ et al. analyse the properties of foamed concrete reinforced with small sized glazed hollow beads; J. Mikolaj et al. present an optimization of life cycle extension of asphalt concrete mixtures in regard to material properties, structural design, and economic implications; J. Wu et al. investigate numerically the elf-compacting concrete by an enhanced Lagrangian particle method; Y. Peng et al. present a new numerical concrete model, random convex aggregate model, by using the base force element method on potential energy principle, to simulate the experiment under uniaxial compression for recycled aggregate concrete; and G. Ma et al. present an experimental and numerical study of conventional solid reinforced concrete beams that were modified to slotted beams for consideration as thermal insulation structural components. 
The chemical attack of concrete structures and other building materials is analysed in detail by some authors. A. S. Guimarães et al. study the effect of salt solutions and absorption cycles in the capillary and drying coefficient of red brick samples with different joints; B. Shen et al. present a mechanical performance and chloride diffusivity of cracked RC specimens exposed to freeze-thaw cycles and intermittent immersion in seawater; M. J. Kim et al. present a study that concerns the influence of $\mathrm{C} 3 \mathrm{~A}$ in cement on chloride transport in reinforced concrete; $\mathrm{M}$. Jinchuan et al. study the influence of $\mathrm{MgO}$ and hybrid fiber on the bonding strength between reactive powder concrete and old concrete; and J. M. P. Q. Delgado et al. present a critical review of salt damage in building materials with a technical application of rising damp treatment in historical buildings.

Besides those, there are several interesting topics in the issue of cement material. M. Rao et al. investigate cementbased materials by comparing the strength and microstructure of pastes and mortar containing limestone powder or low quality fly ash; K. S. Kannan et al. present an experimental investigation on strength development of cement with cenosphere and silica fume as pozzolanic replacement; I. Iskhakov and Y. Ribakov analyse the structural phenomenon of cement-based composite elements in ultimate limit state; and $\mathrm{H}$. Choi and B. Cho present a new composite model that is appropriate for particle conditions by considering the balance of the hydration products of cement and expansive additive and the stress redistribution phenomenon of hydration products newly generated by the progress of hydration.

Another important issue is the ecology of building materials. J. Estévez-Cimadevila et al. analyse the performance of wooden structural floors equipped with the self-tensioning system patented by the authors, consisting of a force multiplying mechanism connected to a self-tensioning tendon, which is activated automatically when the load is applied to the structural element; F. Guo et al. present an experimental novel magnetorheological material defined as magnetorheological Silly Putty prepared by dispersing soft magnetic particles into Silly Putty matrix with shear stiffening property; H. Danso investigates the influence of compacting rates on the properties of compressed earth blocks; and D. Kim et al. present reasonable ways of improving the dredged soils in the Saemangeum area so that they can be used for vegetation of land plants.

Studies with asphalt are presented by A. Vaitkus et al. who analyse the performance of soft asphalt and double Otta seal within first three years; Y. Yang and Y. Cheng study the influence of different doses on the performance of modified asphalt, including softening point, penetration, ductility $\left(5^{\circ} \mathrm{C}\right)$, and viscosity at $135^{\circ} \mathrm{C}$ and $165^{\circ} \mathrm{C}$. Moreover, the authors also discuss the modification mechanism of modified asphalt through the fluorescence microscope; and W. Huang et al. present an image-based micromechanical modelling approach to predict viscoelastic behaviour of asphalt mixture.

Another considerable number of papers address new numerical research in advanced building materials. Y. Xu et al. analyse experimentally and numerically the fretting fatigue behaviour for steel Q235 single-lap bolted joints; M. Vild and M. Bajer present experimental and numerical research into the strengthening of steel columns under load using welded plates; $\mathrm{H}$. Lin et al. present a control parametric analysis on improving park restoring force model and damage evaluation of high-strength structure and M. R. Kaloop and J. W. Hu investigate numerically a novelty wavelet application for damage detection of regular and irregular building structures under seismic load effects.

Finally, B. Kromoser and P. Huber describe different pneumatic formwork systems invented in the past 100 years and present the latest developments in this area. The many types of possible applications are divided into three categories in order to obtain a clearer overview. Z. Luo et al. present the two mainstream directions in the real estate industry for the green building and housing industrialization. C. Peng and J. Yang study the structure, mechanism, and application of vacuum insulation panels in Chinese buildings.

We hope that readers of this special issue will find not only accurate data and updated reviews on the building technologies and construction materials field area, but also important questions to be resolved. This special issue includes both theoretical and experimental developments, providing a self-contained major reference that is appealing to both the scientists and the engineers. At the same time, these topics meet a variety of scientific and engineering disciplines, such as chemical, civil, agricultural, and mechanical engineering.

\section{J. M. P. Q. Delgado Robert Černý \\ A. G. Barbosa de Lima A. S. Guimarães}

\section{References}

[1] J. M. P. Q. Delgado, R. Cerný, A. G. B. de Lima, and A. S. Guimarães, "Advances in building technologies and construction materials," Advances in Materials Science and Engineering, vol. 2015, Article ID 312613, 3 pages, 2015. 

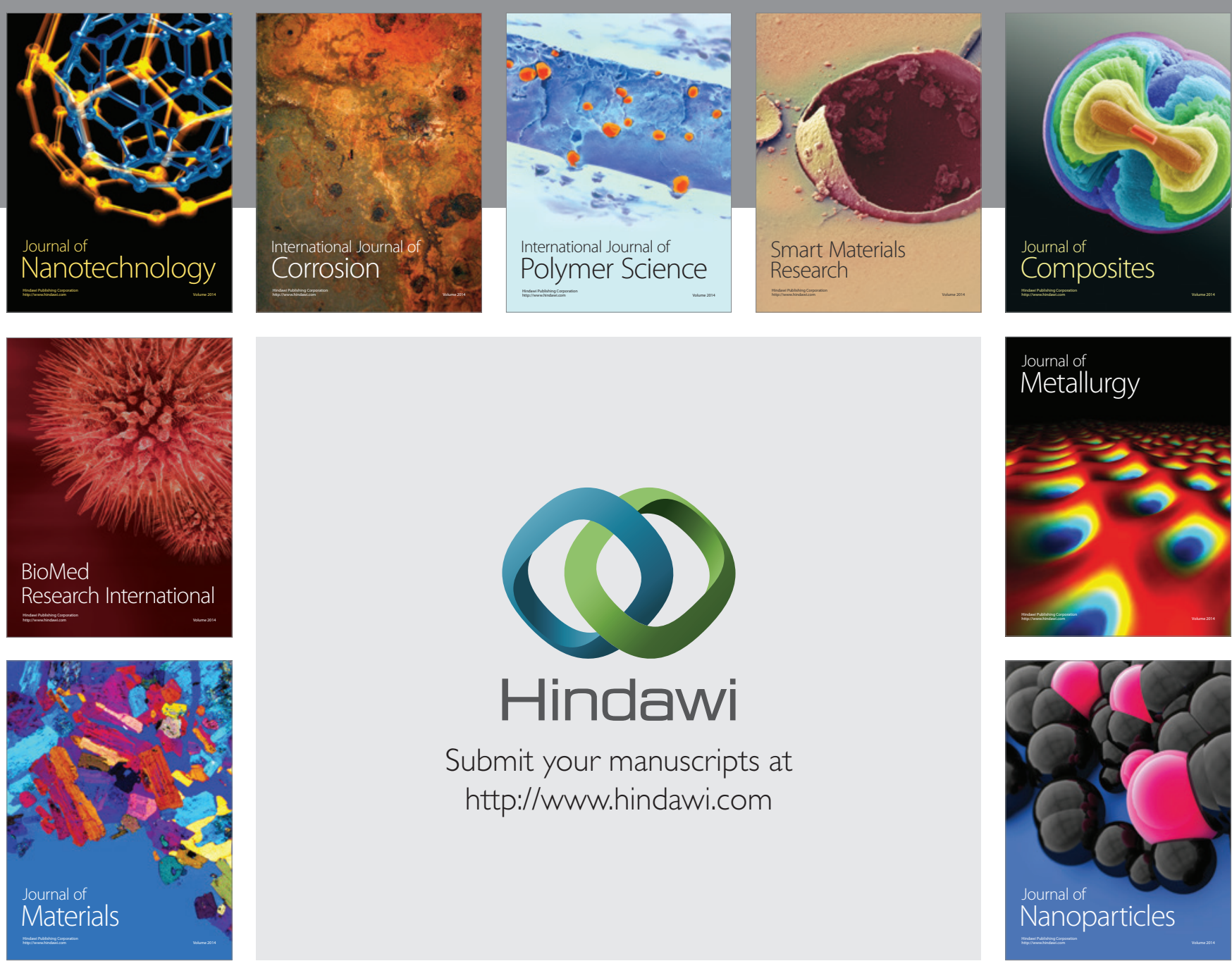

\section{Hindawi}

Submit your manuscripts at

http://www.hindawi.com

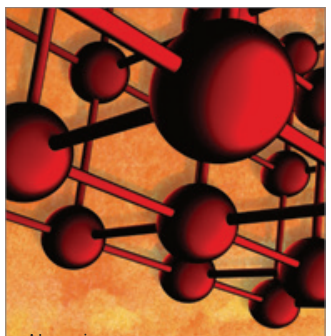

Materials Science and Engineering
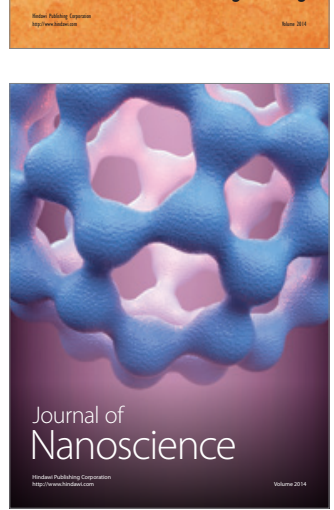
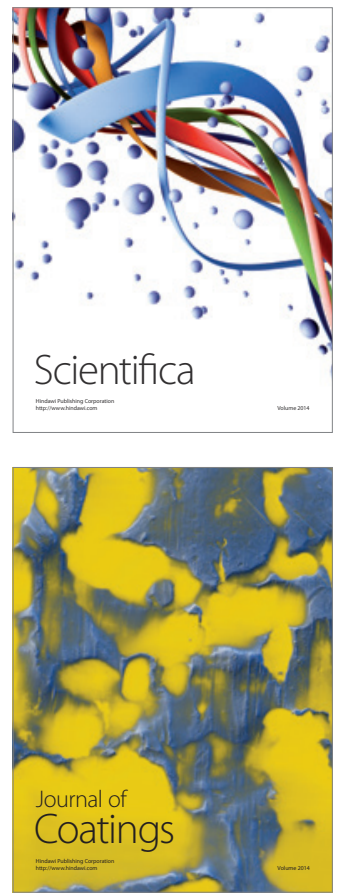
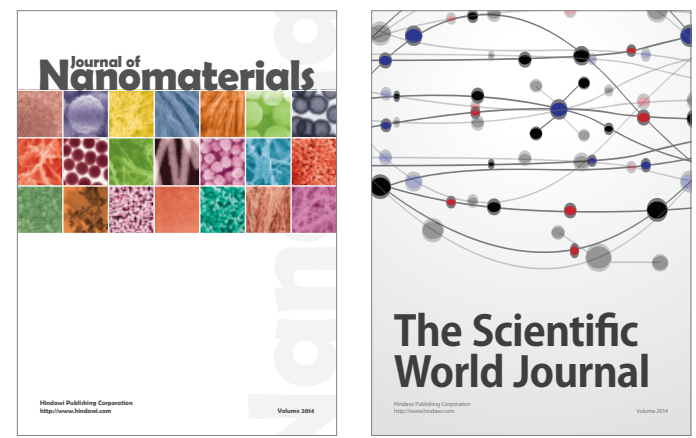

The Scientific World Journal
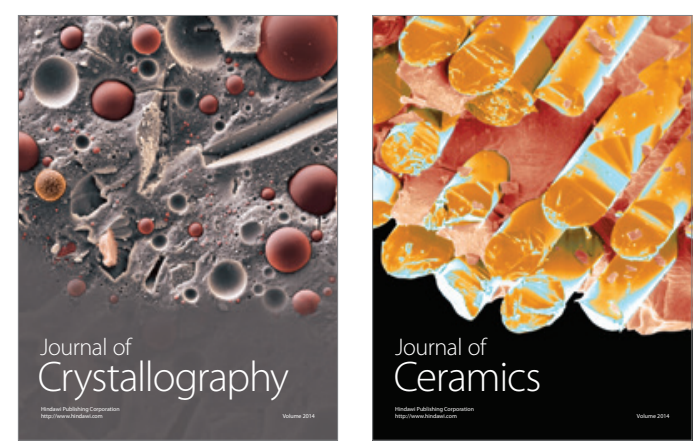
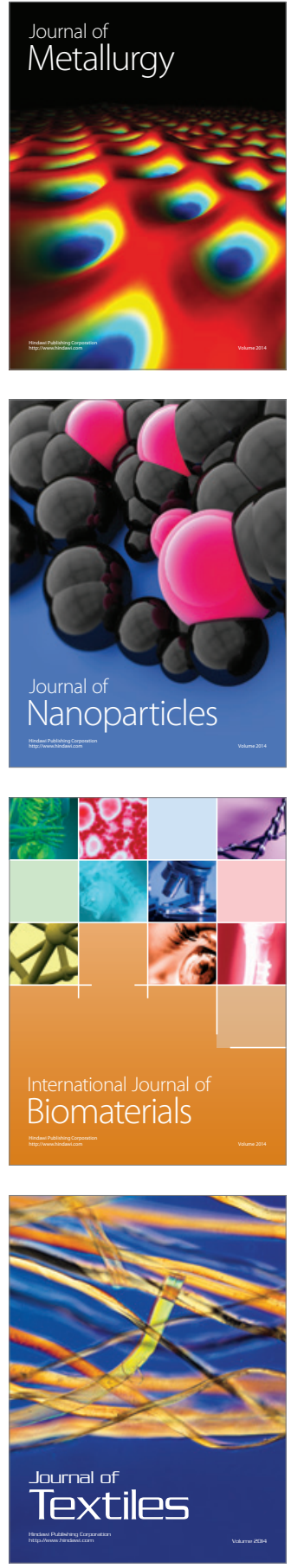